\title{
The sustainability of shared mobility: can a platform for shared rides reduce motorized traffic in cities?
}

\author{
Alejandro Tirachini $\left({ }^{1,2, *}\right)$ \\ Emmanouil Chaniotakis $\left({ }^{3}\right)$ \\ Mohamed Abouelela $\left({ }^{4}\right)$ \\ Constantinos Antoniou ( $\left.{ }^{4}\right)$
}

(1) Transport Engineering Division, Civil Engineering Department, Universidad de Chile, Santiago, Chile

(2) Instituto Sistemas Complejos de Ingeniería, Santiago, Chile

(3) MaaSLab, Energy Institute, University College London, London, UK

${ }^{(4)}$ Chair of Transportation Systems Engineering, Technical University of Munich, Munich, Germany

$\left({ }^{*}\right)$ Corresponding author:

Alejandro.tirachini@ing.uchile.cl,m.chaniotakis@ucl.ac.uk,mohammed.abouelela@tum.de, c.antoniou@tum.de

\section{Citation:}

Tirachini, A., Chaniotakis, E., Abouelela, M. and Antoniou, C. (2020) The sustainability of shared mobility: can a platform for shared rides reduce motorized traffic in cities? Transportation Research Part C: Emerging Technologies 117, 102707. https://doi.org/10.1016/j.trc.2020.102707.

\begin{abstract}
Studies in several cities indicate that ridesourcing (ride-hailing) may increase traffic and congestion, given the substitution of more sustainable modes and the addition of empty kilometers. On the other hand, there is little evidence if smartphone apps that target shared rides have any influence on reducing traffic levels. We study the effects of a shared-mobility service offered by a start-up in Mexico City, Jetty, which is used by travelers to book a shared ride in a car, van or bus. A large-scale user survey was conducted to study trip characteristics, reasons for using the platform and the general travel choices of Jetty users. We calculate travel distance per trip leg, for the current choices and for the modes that riders would have chosen if the platform was not available. We find that the effect of the platform on vehicle kilometers traveled (VKT) depends on the rate of empty kilometers introduced by the fleet of vehicles, the substitution of public versus private transport modes, the occupancy rate of Jetty vehicles and assumptions on the occupancy rate of substituted modes. Following a sensitivity analysis approach for variables with unavailable data, we estimate that shared rides in cars increase VKT (in the range of 7 to $10 \mathrm{~km} /$ passenger), shared vans are able to decrease VKT (around -0.2 to $-1.1 \mathrm{~km} /$ passenger), whereas buses are estimated to increase VKT (0.4 to $1.1 \mathrm{~km} /$ passenger), in our preferred scenarios. These results stem from the tradeoff between the effects of the occupancy rates per vehicle (larger vehicles are shared by more people) and the attractiveness of the service for car users (shared vans attract more car drivers than buses booked through Jetty). Our findings point to the relevance of shared rides in bigger vehicles such as vans as competitors to low occupancy car services for the future of mobility in cities, and to the improvement of public transportation services through the inclusion of quality attributes as provided by new shared-mobility services.
\end{abstract}

Keywords: Shared mobility; Vanpooling; ride-splitting; public transportation; Transportation Network Companies, ride-hailing, 


\section{Introduction}

The fast-increasing availability of information and communication technologies (ICT) and positioning tools in smartphones has enabled a growing number of mobility innovations and services (Shaheen et al., 2016). The spread of smartphones and mobile internet connections has facilitated the expansion of mobility options that have existed for a longer time, such as shared bicycles and shared cars. There are new mobility technologies that depend entirely on the real-time connectivity between drivers and passengers to agree on a trip. One of these technologies is ridesourcing (also known as ride-hailing ${ }^{1}$ ), in which a traveler is matched through a mobile application with a driver, following optimization procedures to reduce waiting time of users (Shaheen, 2018).

In the pertinent literature, the study of new ICT-enabled technologies includes the analysis of the effects of ridesourcing on traffic levels (Erhardt et al., 2019; Henao and Marshall, 2019; Tirachini and GomezLobo, 2020), energy consumption (Wenzel et al., 2019), social equity (Brown, 2018) and replacement/complementarity of/to public transportation (Clewlow and Mishra, 2017; Hall et al., 2018; Graehler et al., 2019). An extensive review of these topics is presented in Tirachini (2019). Another strand of literature deals with the regulation of ridesourcing services, either from a policy-oriented perspective (Beer et al., 2017; Alonso Ferreira et al., 2018) or from economic models that aim at finding optimal values of trip fares and fleet sizes in first-best and second-best environments (Zha et al., 2016). A special type of ridesourcing service is ride-splitting (also known as shared or pooled ridesourcing), in which users, for a fare discount, share a ride with other passengers (unknown to them) that have different origins and destinations, therefore detours on the shortest path may be induced. Research on ride-splitting is still rare, a notable exception is the study from Li et al. (2019), which analyzes detailed data of Didi ExpressPool in Chengdu, China, and estimated that, on average, ride-splitting saves $22 \%$ of vehicle-hours of traffic, relative to the situation in which the same trips would have been made by using (unshared) ridesourcing.

Other services for shared mobility use shared shuttles or vans that operate on flexible or semi-fixed routes and can be reserved in advance or on-demand. Specifically, vanpooling, is a transportation service first introduced in 1970 (Kircher and Wapensky, 1978), for groups of people who live in the same area, commute to the same directions and choose to commute as a group in a van (Ditmore and Deming, 2018). App-based vanpool services have become somewhat popular worldwide, including Berlin (Door2door and Allygator Shuttle), New York (Via Van), London (Ford) and Beijing (Didi Chuxing). Dynamic vanpooling can be a competitive mode of transport, as generally, it is more affordable than driving a private car or hailing a taxi (Dong et al., 2018). A general analysis of alternative shared-mobility modes, including vanpooling, carpooling, and ride-splitting, is found in Shaheen and Cohen (2019).

As current research increasingly shows, ridesourcing results in increased road traffic levels, in terms of vehicle kilometers traveled (VKT) (Henao and Marshall, 2019; Tirachini and Gomez-Lobo, 2020) and congestion delays (Nie, 2017; Agarwal et al., 2019; Erhardt et al., 2019). This issue casts serious doubts on the sustainability effects of ridesourcing applications for urban mobility (Tirachini, 2019). The question that begs is if there are ways in which this type of shared-mobility innovation, could reduce or at least keep constant traffic levels in cities (at the same time that it provides several quality attributes to riders). Such an outcome would certainly increase social welfare and pave the way for the inclusion of these platforms as part of the multimodal transport portfolio to fulfill the mobility needs of citizens, for example, in complementarity to mass public transportation systems. An increase in vehicle occupancy rates by

\footnotetext{
${ }^{1}$ Service providers are commonly called Transportation Netowrk Companies (TNCs).
} 
ridesourcing, achievable through ride-splitting, could imply a reduction in VKT, as predicted by Tirachini and Gomez-Lobo (2020) using simulation. However, the increase in vehicle occupancy rates that is achieved with ride-splitting is not by itself enough to decrease VKT, as evidence from China and the United States shows that shared ridesourcing users are more likely to replace public transportation trips than (un-shared) ridesourcing users (Lavieri and Bhat, 2019; Tang et al., 2019). None of these studies attempt to estimate the effect of shared rides on the number of vehicle kilometers traveled in a city, using actual trip-level passenger data. The present study aims to bridge this gap in the literature, by estimating if a platform designed for shared rides can actually reduce motorized traffic levels. We perform a large-scale user survey that includes questions regarding socioeconomic characteristics, travel behavior, reasons to share rides and characteristics of the shared trip performed, including modes to access and egress, total travel time and mode substitution. The latter information is used to estimate the effects of the platform in traffic levels. and congestion. We focus on an urban environment of massive scale, Mexico City, and analyze the case of Jetty, an app-based platform to book shared trips in cars, vans and buses. With Jetty, users are picked up and dropped off in designated stops and are informed in advance about the type of vehicle, license plate of vehicle and pick-up time. Jetty tickets are more expensive than those of the traditional public transportation (PT) operators but cheaper than ridesourcing or taxi trips.

The rest of the paper is organized as follows. Section 2 describes the data and methods used for this research, Section 3 summarizes general findings, while Section 4 focuses on the VKT effects of Jetty. Conclusions and directions of further research are discussed in Section 5.

\section{Data and methods}

\subsection{User Survey Design}

A user survey has been designed that explores mobility choices, socioeconomic characteristics of the users, reasons to use a platform for shared trips and alternative modes, should the platform be unavailable. The survey is structured in three parts:

(i) information about the user's latest trip, such as trip purpose, modes that were used, including parking and walk, if relevant;

(ii) information about the general travel patterns of the individual, including use of shared ridesourcing, such as the trip rate per mode, time use information, and the factors that affect the use of Jetty, and

(iii) demographic information, such as occupation, education, age, gender, household size and income, whether they have a driver's license, as well as access to car.

The survey was designed in such a way that the results obtained by each user can be linked to trip and socio-demographic data collected by the service providers. This has been achieved with the use of tokens that allowed the definition of a unique Uniform Resource Locator (URL) for each user. Aiming at an independent data collection that would respect privacy without compromising research independency, the process followed included: a) contact the service provider and establish the necessary legal basis for data exchange; b) receive a list of anonymized IDs and trip characteristics data to be linked with the data collected from the survey; c) create individualized URLs for each user; d) distribute the survey through the service provider communication channels (e.g. through the mobile-phone app, or through email). In general, it should be noted that for research integrity, the results of the survey should not be shared with 
the data provider before receiving all available user data. Random respondents were offered vouchers for free Jetty rides after completion of the survey.

\subsection{Study area and description of the service provider}

The Metropolitan Area of Mexico City (Zona Metropolitana del Valle de Mexico, ZMVM in Spanish) was chosen as a prominent case for the implementation of the survey. It has a population of 21 million people, including the municipalities of Mexico City and the conurbations State of Mexico and Tizayuca. In ZMVM, the latest household origin-destination survey (INEGI, 2017) shows that $41 \%$ of households own a private car (approx. 3 million cars) and that on a normal working day, 34.5 million trips are made within the metropolitan area. Regarding modal split, $40 \%$ of trips are made by public transportation (PT), 32\% by walking, $19 \%$ by private car, and $5 \%$ by taxis (including ridesourcing). Public transportation comprises of a Metro network (12 lines, $227 \mathrm{~km}$.), Bus Rapid Transit (BRT, Metrobus) and other formal bus services such that the Ecobus, plus thousands of poorly regulated, lower quality colectivos, which include standard size buses, microbuses and vans or "combis". Colectivos are the largest PT mode in terms of trips and spatial coverage, as more than 11 million trips are made daily using their services ( $33 \%$ of total trips).

Jetty, launched in 2017, is an app-based platform to book a seat in a shared vehicle. Jetty does not own any vehicle, but rather makes deals with associations of vehicle operators in Mexico City and State of Mexico (part of the metropolitan area around Mexico City) which join Jetty. Drivers must have a work contract, the operator needs to have proper insurances and vehicles that are relatively new, well equipped and maintained. Jetty keeps a fraction of the fare charged and the rest is transferred to the transport operators ${ }^{2}$. In our sample, average car, van and bus fares in Jetty are 67, 69 and 43 Mexican Pesos (MXN), respectively, whereas the single-ride fare for colectivos, Metro, Metrobus and Ecobus is between 5 and 7 Mexican Pesos ( 1 USD= 19 MXN, 1 Euro=21 MXN). In the city, Jetty is a small player, with 37000 tickets sold in November 2018 (Flores Dewey, 2018), which is equivalent to roughly 1 in every 20,000 trips in ZMVM. At the time of writing, Jetty only operates during peak periods mainly for commuting trips. Jetty works with several types of vehicles, which we categorize in three groups according to vehicle size:

- Cars, with a capacity to carry between 3 and 6 passengers

- Vans, with a capacity to carry between 13 and 17 passengers

- Buses, with a capacity to carry between 30 and 45 passengers

Figure 1 shows a map of the Jetty service area in ZMVM as per May 2019. The points in green are the pickup stops, while the points in gray are the drop off stops. Jetty has fixed routes, i.e., passengers are told in advance about the pickup stop, where they have to board vehicles, and they know in advance the route that the vehicle will follow until their drop off stop. In this way, the service provided by Jetty is different from more flexible on-demand shared services with adaptive routes, such as ride-splitting (shared ridesourcing); Jetty is closer to a traditional fixed-route bus service, and therefore its modal substitution might be different from that of ride-splitting. Jetty has two main destination areas in the morning: the districts of Santa Fe and Polanco, which are characterized by being important job agglomerations. Santa Fe is one of the main business districts of Mexico City whereas Polanco is an

\footnotetext{
${ }^{2}$ A more detailed description of Jetty is found in the International Transport Forum (ITF) Discussion Paper written by one of the founders of Jetty (Flores Dewey, 2018).
} 
affluent neighborhood and shopping area. In the afternoon, the routes start from these zones of employment to the points where the users started their trips in the morning, which are spread in several districts in the north, center and south of the city, as Figure 1 shows.

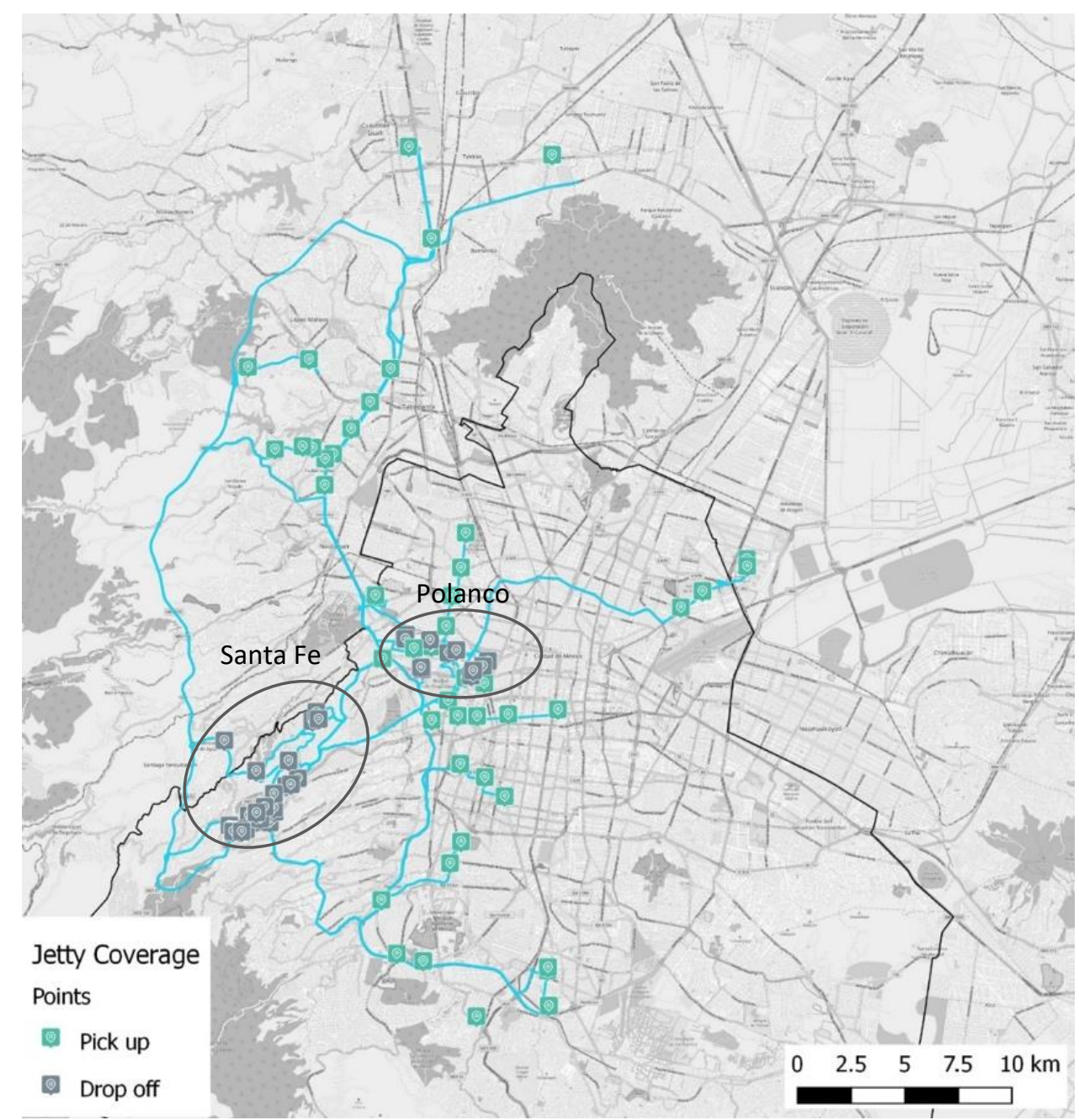

Figure 1: Geographical coverage of Jetty services (source: Jetty)

\subsection{User survey deployment}

The authors contacted Jetty in order to launch a research collaboration that would be based on data exchange and the deployment of a survey to Jetty users. After signing a Memorandum of Understanding and a Data Exchange agreement, Jetty provided a list of all the riders that had used Jetty in the past 6 months prior to the survey. The number of users that were invited to participate in the survey were 14093. The user URLs were sent back, and the survey was distributed by sending personalized emails. The survey was conducted online using the open-source tool Limesurvey, from an account administered by the Technical University of Munich. The instance of Limesurvey was hosted by the authors and only they had access to the data collected. Before the full deployment, a pilot study was conducted, for which the survey was sent to 50 users. The final set of responses was collected between May $30^{\text {th }}$ and June $11^{\text {th }}, 2019$ after sending the survey individually to participants, as well as a reminder after the first week of data collection. 
Distribution of the survey resulted in 3091 responses (approx. 23\% response rate) out of which 2484 were completed. After an initial screening and by joining with the data provided by Jetty, the dataset that was used for the analysis included 2169 participants. The linked data provided by Jetty included all trips performed by the survey respondents for a period of 6 months before the survey; showing the trips' start and end location (WGS84 coordinates), start time, end time, type of vehicle used, trip ID and route ID for each user. Also, the operator provided the average capacity (number of seats) per vehicle type for the whole month of May 2019 to be used in the VKT calculation, and the definition and length of routes.

\subsection{Procedure to estimate travel distances for Jetty alternatives}

For estimating the effects of shared ridesourcing operators on VKT in Mexico City (Section 4), we use responses to the question "If Jetty was not available, how would you have made your latest Jetty trip?", to find the alternative mode. The choice set consists of 15 options, from which respondents could choose up to three. It was explicitly explained that choice of more than one mode, means combination (multimodal trip). Options like "I would not have traveled" and "Others" were available. Respondents were also asked to state the total travel time that they would have experienced in that case. The modes to choose from were: Car (driver); Car (Passenger); Taxi; App-based Taxi (e-hailing and ridesourcing); Shared taxi; metro; Suburban train; Metrobus; Ecobus; Bus; Minibus; Combi and motorcycle. A very small percentage of responders (3\%) specified the option "others". These other modes, in most cases, were variations within the given set of modes of transport and they were mapped into the main choice set according to their similarities. Users also reported their home and work zip codes in the survey. This information was geocoded using a Google Maps geocoding package ${ }^{3}$ to get startpoint and endpoint coordinates for each trip. Around $51 \%$ of the respondents (1257 users) reported valid origin and destination zip codes that could be used in the geocoding process.

Given survey related limitations (number of questions/alternatives, fatigue), there was no question from which we could directly extract the mode sequence or any question on the distance traveled in each alternative mode, if more than one mode would have been used instead of Jetty. Thus, the 13 modes of the choice set were grouped into three main groups, to calculate the total trip distance and the share of each of the modes per trip. The choice of the modes composing each group depends mainly on the flexibility of the route of each mode, and the method used to calculate the corresponding VKT. The three groups of modes are specified as follows:

Group 1: Shortest Path Group: This group consists of car driving, car passenger, taxi, ehailing/ridesourcing, shared taxi, bus, microbus, combi, and motorcycle, and different combinations of those modes. The main characteristic of this group in Mexico City was that they do have flexible routes and tend to use the shortest path to travel. The Google Maps direction API service was used to calculate the total trip distance between the origin and destination of each trip, assuming travel time shortest-path routes. For the case of PT modes such as bus, microbus and combi, a deviation factor over the shortest path is added to the shortest path calculation, in order to compute VKT, as explained in Section 4.

\footnotetext{
${ }^{3}$ mapsapi: 'sf'-Compatible Interface to 'Google Maps' APIs. R package version 0.4.2. Available at https://CRAN.Rproject.org/package=mapsapi, accessed January $13^{\text {th }}, 2020$
} 
Therefore, given the uncertainty on distances per mode, for the assignment of total travel distance when the trip reported is composed by a combination of two or three of the modes of this group, the following two scenarios are made and compared:

- Scenario A: The total travel distance of PT modes is larger than those of low occupancy modes. This assumption reflects a situation in which a low occupancy vehicle such as a private car, a taxi or ridesourcing is used to access PT vehicles, e.g., a bus, microbus or combi. This PT vehicle covers the largest part of the trip. We assume that when we have either one or two public transportation vehicles and one low occupancy vehicle (cars, taxis, e-hailing, ridesourcing), of the total distance, $3 / 4$ is made by public transportation modes and $1 / 4$ is made by low occupancy vehicles. In case of having two low occupancy vehicles and one public transportation vehicle, distance is divided as $1 / 4$ for each low occupancy vehicle and $1 / 2$ for the public transportation vehicle.

- Scenario B: The total trip distance is divided equally between the number of modes reported for each trip. This is thought to be a less conservative scenario for VKT analysis than A, for example, $B$ assumes equal distances when traveling by ridesourcing and microbus, even though the former is much more expensive than the latter. In $A$, the contribution of Jetty to potentially reduce VKT is lower than in $B$, because in $B$ the number of VKT that the rider would have added to the network if Jetty is not available is larger than in A.

Group 2: Rail Group: This group includes the trips reported to be (partially) performed by metro or suburban train. The locations of the stations of those two modes were obtained from General Transit Feed Specifications files (GTFS) ${ }^{4}$ and Google Maps. The shortest path distance from each trip's start- and endpoint to the nearest station was calculated using the Google Maps API. The summation of distance from the trip's start- and endpoint to the nearest station was divided by the remaining number of modes, also using the two alternative scenarios $\mathrm{A}$ and $\mathrm{B}$.

Group 3: BRT Group: This group includes trips reported to be (partially) performed by Ecobus or Metrobus. The main characteristic of this group was that they are running on fixed routes and that, unlike microbuses and combis, the routes of Ecobus and Metrobus do appear in Google Maps. The Google Maps Transit API was used to calculate the travel distance for each mode. The obtained distances were distributed to the reported number of modes on a case-by-case basis.

\subsection{Latest Jetty trip}

The survey's response date and time of each user were checked against their survey completion time. The last Jetty trip that took place before the survey completion time was considered as the latest Jetty trip for VKT analysis. The Jetty trips performed by users consisted of three stages: (a) from origin to Jetty's pickup point; (b) the Jetty ride and (c) from Jetty's drop-off point to destination. Jetty provided the middle leg for the survey respondents, including the pickup and drop-off locations coordinates to be used to calculate the access and egress distance. Additionally, the respondents reported the modes used to access their last Jetty trip pickup point and to egress from the drop-off points to their final destination, apart from reporting estimated travel time for access and egress (walking; bicycle; car; e-hailing/ridesourcing; taxi; Metro; minibus; combi; Metrobus). Similarly, to the Jetty alternative modes (Section 2.3), the modes were divided into the same three main groups as for access/egress modes, based on their route flexibility and the method used to calculate the corresponding VKT.

${ }^{4}$ https://transitfeeds.com/p/mexico-city-federal-district-government/70?p=3, accessed July 1 ${ }^{\text {st }}, 2019$ 


\section{Descriptive analysis}

\subsection{Descriptive statistics}

The sociodemographic characteristics of our sample are presented in Table 1. Our sample is relatively similar to the general Mexico City sociodemographics in terms of age, gender and household size, according to the official information published by the National Institute of Statistics, Geography and Informatics of Mexico (INEGI, 2015), as 52\% of the population in Mexico City is composed by women, the median age is 35 years old and the median household size is 3.2 inhabitants/household (INEGI, 2015). However, there is a strong difference in terms of income, car ownership and education level between our sample and the general population. In our sample, middle- and high-income people are overrepresented, compared to the general population in Mexico City, as the median monthly income of riders in our sample is around 1000USD ${ }^{5}$ and the average income is even larger, whereas in Mexico City average income is slightly over USD 500 per month ${ }^{6}$. This is consistent with the characteristics of Jetty, which offers a higher level of comfort than traditional PT services (combis and microbuses), but for a higher price. Additionally, the majority of Jetty users who responded to the survey are highly educated (91.7\%), as opposed to $32.1 \%$ for Mexico City population (INEGI, 2015). Additionally, $80 \%$ of the survey respondents have at least one vehicle available at home, almost double the rate for the population average (41\%). This also shows the potential of such a platform to replace trips that would otherwise be made by car. Table 2 shows that 35\% of Jetty users in our sample replace trips that are performed by car (as a passenger or as a driver), and $67 \%$ of the sample replace trips that would have been made, in at least one stage, in low occupancy vehicles (personal cars, taxis, ridesourcing).

${ }^{5}$ Currency in Table 1 is in USD (in the survey, currency was Mexican Pesos MXN, 1 USD= 19 MXN in July 2019)

${ }^{6}$ https://www.observatoriolaboral.gob.mx/static/estudios-publicaciones/Panorama profesional estados.html, accessed July $1^{\text {st }}, 2019$ 
Table 1: Statistics of the sample $(n=2484)$

\begin{tabular}{|c|c|c|c|c|c|c|c|}
\hline Variable & Levels & Freq & Pct \% & Variable & Levels & Freq & Pct \% \\
\hline \multicolumn{4}{|l|}{ Age } & \multicolumn{4}{|c|}{ Household Income } \\
\hline & $18-25$ & 376 & $15.1 \%$ & & Less than $525 \$$ & 150 & $6.0 \%$ \\
\hline & $26-35$ & 1143 & $46.0 \%$ & & $525 \$-1050 \$$ & 410 & $16.5 \%$ \\
\hline & $36-45$ & 635 & $25.6 \%$ & & $1050 \$-1575 \$$ & 417 & $16.8 \%$ \\
\hline & $46-55$ & 239 & $9.6 \%$ & & $1575 \$-2100 \$$ & 323 & $13.0 \%$ \\
\hline & $56-65$ & 58 & $2.3 \%$ & & $2100 \$-2625 \$$ & 224 & $9.0 \%$ \\
\hline & More than 65 & 6 & $0.2 \%$ & & $2625 \$-3150 \$$ & 179 & $7.2 \%$ \\
\hline & Missing & 27 & $1.1 \%$ & & $3150 \$-3675 \$$ & 107 & $4.3 \%$ \\
\hline \multicolumn{4}{|l|}{ Gender } & & More than $3675 \$$ & 149 & $6.0 \%$ \\
\hline & Female & 1212 & $48.8 \%$ & & Missing & 525 & $21.1 \%$ \\
\hline & Male & 1262 & $50.8 \%$ & \multicolumn{4}{|c|}{ Driving license } \\
\hline & Other & 10 & $0.4 \%$ & & Yes & 1901 & $76.5 \%$ \\
\hline & Missing & 00 & $0.0 \%$ & & No & 583 & $23.5 \%$ \\
\hline \multicolumn{4}{|c|}{ Household Size. } & & Missing & 00 & $0.0 \%$ \\
\hline & 1 & 122 & $4.9 \%$ & \multicolumn{4}{|c|}{ Cars in Household } \\
\hline & 2 & 556 & $22.4 \%$ & & 0 & 520 & $20.9 \%$ \\
\hline & 3 & 582 & $23.4 \%$ & & 1 & 1130 & $45.5 \%$ \\
\hline & 4 & 630 & $25.4 \%$ & & 2 & 628 & $25.3 \%$ \\
\hline & 5 & 288 & $11.6 \%$ & & 3 or More & 206 & $8.3 \%$ \\
\hline & 6 & 113 & $4.6 \%$ & & Missing & 00 & $0.0 \%$ \\
\hline & 7 & 94 & $3.8 \%$ & \multicolumn{4}{|c|}{ Education Level } \\
\hline & Missing & 99 & $4.0 \%$ & \multicolumn{2}{|c|}{ Masters or Doctorate } & 378 & $15.2 \%$ \\
\hline \multicolumn{4}{|c|}{ Personal Income } & \multicolumn{2}{|c|}{ Bachelor or Professional } & 1813 & $73.0 \%$ \\
\hline \multicolumn{2}{|c|}{ Less than $525 \$$} & 320 & $12.9 \%$ & \multicolumn{2}{|c|}{ Technical Career } & 134 & $5.4 \%$ \\
\hline \multicolumn{2}{|c|}{$525 \$-1050 \$$} & 878 & $35.4 \%$ & \multicolumn{2}{|c|}{ High School or Baccalaureate } & 126 & $5.1 \%$ \\
\hline \multicolumn{2}{|c|}{$1050 \$-1575 \$$} & 484 & $19.5 \%$ & \multicolumn{2}{|c|}{ Primary } & 3 & $0.1 \%$ \\
\hline \multicolumn{2}{|c|}{$1575 \$-2100 \$$} & 216 & $8.7 \%$ & \multicolumn{2}{|c|}{ Secondary } & 7 & $0.3 \%$ \\
\hline \multicolumn{2}{|c|}{$2100 \$-2625 \$$} & 90 & $3.6 \%$ & \multicolumn{2}{|c|}{$\begin{array}{l}\text { I did not complete formal } \\
\text { education }\end{array}$} & 3 & $0.1 \%$ \\
\hline \multicolumn{2}{|c|}{ More than $2625 \$$} & 94 & $3.8 \%$ & \multicolumn{2}{|c|}{ Missing } & 20 & $0.8 \%$ \\
\hline \multicolumn{2}{|c|}{ Missing } & 402 & $16.2 \%$ & \multicolumn{4}{|c|}{ Employment Status } \\
\hline & & & & Fulltime & & 2127 & $85.4 \%$ \\
\hline & & & & Part time & & 99 & $3.60 \%$ \\
\hline & & & & Full time & & 32 & $1.3 \%$ \\
\hline & & & & Full time & and Part time study & 72 & $2.9 \%$ \\
\hline & & & & Part time & and Part time study & 49 & $2.0 \%$ \\
\hline & & & & Other & & 105 & $4.9 \%$ \\
\hline & & & & Missing & & 00 & $0.0 \%$ \\
\hline
\end{tabular}

Note: Income is given in USD (\$)

\subsection{Reasons to choose Jetty}

The attributes that influence users' choices are examined in this section. These have been identified based on the reasons why survey respondents use Jetty, as shown in Figure 2. Various market segmentation factors were examined with the gender of respondents to yield interesting results (see point c). Following 
a descriptive analysis of the survey results, we categorize the reasons to choose Jetty in four broad categories:

a) Conventional mode choice attributes: travel time is ranked third in relevance $166 \%$ of mentions), travel time reliability fourth ( $53 \%$ of preferences) and access/egress time fifth ( $42 \%$ of mentions). Fare is only seventh (36\%), which might be related to the fact that Jetty trips are more expensive than the standard PT in Mexico City, and that the Jetty user profile has an average income larger than that of the general population in Mexico City, as shown in Table 1.

b) Provider-related attributes: this category refers to attributes related to the booking technology and trip management of Jetty. Reserving a seat is the number one attribute as mentioned by users (chosen by $70 \%$ of the sample). This finding can be linked to the crowding and standing valuation in the PT literature, where it has been estimated the increase in willingness to pay to reduce travel time when traveling standing, as compared to sitting, or that riders are willing to have longer travel times if they can secure a seat (e.g., Wardman and Whelan, 2011; Bansal et al., 2019; Márquez et al., 2019). Ease of fare payment, which is done with a credit card through the smartphone app, is eighth with $28 \%$ of mentions, and fare transparency (with Jetty fare is known beforehand, unlike when traveling by taxi) is chosen by 1 out of 5 respondents. In other studies on the adoption of ridesourcing, ease of payment was the number one reason to choose ridesourcing in a sample interviewed in downtown San Francisco (Rayle et al., 2016) and Santiago (Tirachini and del Río, 2019) and was the number seven in a Californian sample (Circella et al., 2018). Quality of vehicles comes sixth with $36 \%$ of preferences; Jetty vehicles are more recent models and are equipped with cameras (Flores Dewey, 2018), which contrasts with the lower quality of combis and microbuses in Mexico City. All in all, we clearly see the relevance of quality-of-service attributes to explain users' preferences, as also known from the public transportation literature (e.g., Tyrinopoulos and Antoniou, 2008; dell'Olio et al., 2011).

c) Security/safety attributes: $70 \%$ of women and $66 \%$ of men selected security, in terms of avoiding the risk of theft, as a reason to choose Jetty. This was the second most chosen attribute overall. Then, security against harassment was chosen by $27 \%$ of women and $4 \%$ of men, this being the attribute with the largest difference between men and women. Lastly, traffic safety is chosen by one out of five respondents. These findings express that a large fraction of riders feel more comfortable in terms of personal security when traveling in Jetty, as compared to other modes in Mexico City, where pickpocketing, theft and sexual harassment are notorious problems for PT users (ONU Mujeres, 2018; Magaloni, 2019).

d) Car-driving related attributes: these are "Use of time while traveling" with $25 \%$ of preferences (place 9) and "avoid parking problems" (place 13), with $8 \%$ for women and $15 \%$ for men. As a comparison to ridesourcing studies, not having to search or pay for parking is ranked between places 4 and 8 as a reason to prefer ridesourcing in the United States (Rayle et al., 2016; Henao, 2017; Circella et al., 2018) and in place 12 in Santiago (Tirachini and del Río, 2019). 


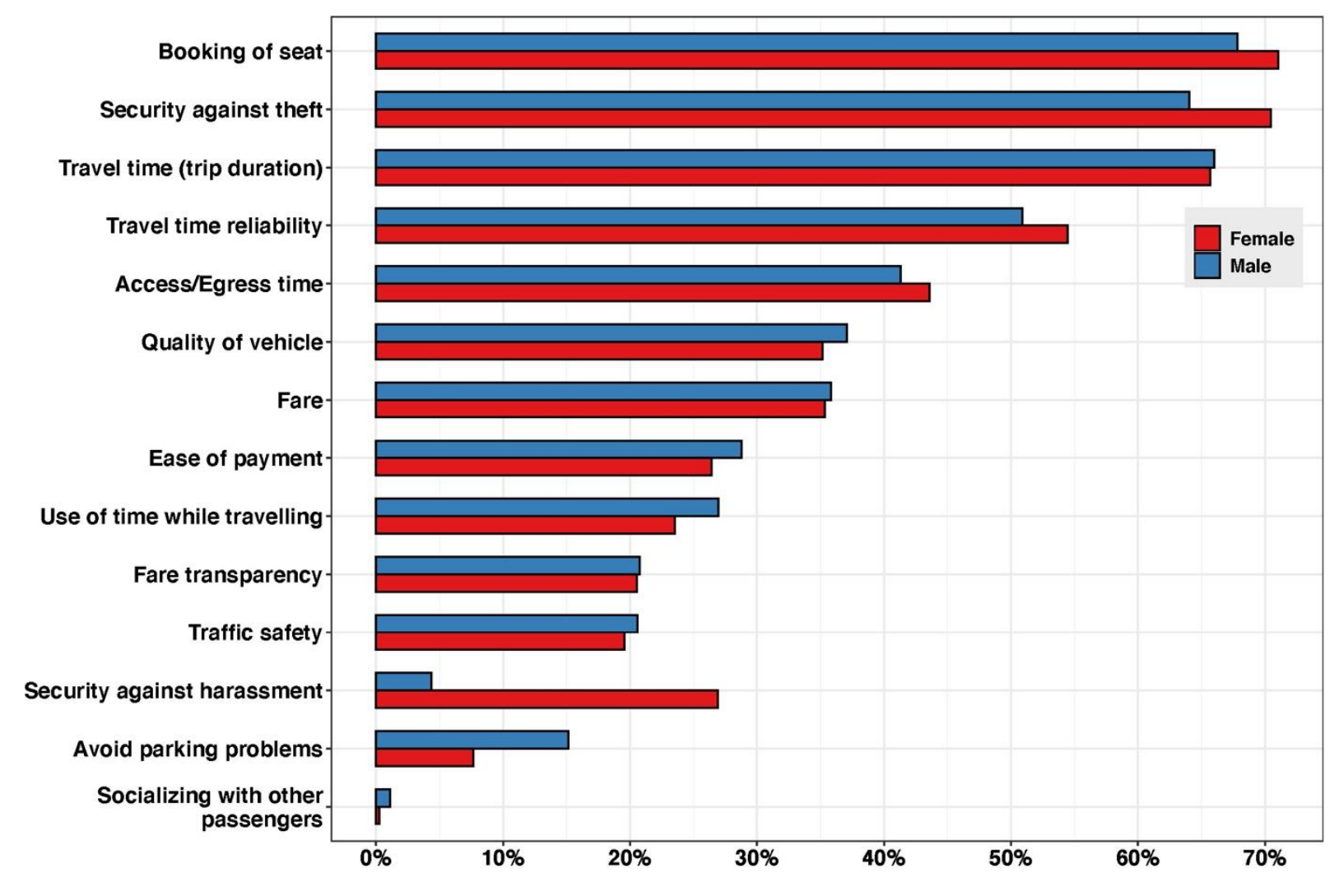

Figure 2: Reasons to use Jetty

\subsection{Total travel times and modal substitution by Jetty users}

The answer to the question "how long would your total travel time be in the trip replaced by your current Jetty choice", shows that the average travel time replaced by the current trip using the shared ridesourcing operator is 97 minutes; and that $85 \%, 66 \%$ and $41 \%$ of users replace trips that would take at least 1 hour, 1.5 hours and 2 hours, respectively, if not made using Jetty, as perceived and estimated by survey respondents. It should be highlighted that these are time perceptions by the users, which might be overestimated. The total duration of Jetty trips includes the reported access and egress times (which are also reported by users, and do not include waiting times) and the Jetty's in-vehicle time (which is extracted from the database of user trips provided by Jetty). The average in-vehicle time in Jetty is 45 minutes, while average access and egress times are 18 and 15 minutes, respectively.

Interesting insights arise concerning modal substitution. First, most respondents replace complex modal configurations by using Jetty instead. Responding to the question "If Jetty would not be available, how would you made your last Jetty trip", $42 \%$ of users in three modes, $32 \%$ of users would need to travel in two modes and only $24 \%$ of respondents state they would make the trip in only one mode. In this question it was explicitly stated that respondents should not count walking as an access mode to motorized modes).

Regarding the specific modes replaced by the latest Jetty trip, the left half of Table 2 shows the rates of modal substitution per mode, in specific, the rate of trips replaced that has at least one stage in the respective mode. The most replaced individual modes are metro $(51.2 \%$ of trips has at least one metro stage), followed by buses (called camion in Mexico City, 32.1\%), car as a driver (25.1\%), ridesourcing/e- 
hailing $(22.4 \%)$ and microbus (18.3\%). When combining modes in categories, we see that $74 \%$ of Jetty trips replace trips with at least one PT stage, 32\% replace trips with at least one stage by car (as driver or passenger), $29 \%$ replace trips with at least one stage in taxi or ridesourcing, and $52 \%$ replace trips with at least one stage in a low occupancy vehicle (private car, taxi, ridesourcing). These numbers make unclear, at first sight, if the use of Jetty increases or decreases VKT in Mexico City, an issue that we analyze in the next section. To further explore the modal substitution patterns of Jetty users, in the right half of Table 2 we show the combinations of modes with the largest number of preferences (respondents were allowed to mark up to three modes, which are used in combination, in the trip replaced by Jetty). It should be noted that the 15 combinations presented account for $77 \%$ of trips in our sample. It can also be observed that one out of five Jetty trips replaces a trip that would have been made in microbus and metro combined, and $11.4 \%$ of trips would have been made by car. Trips by taxi and car plus taxi amount to $10 \%$ of replaced trips. For this selection of combined modes, an aggregation of the modes is made to reduce the number of combinations. The new mode definition is the following:

- Car: car as passenger, car as driver

- Taxi: taxi, e-hailing, ridesourcing

- Microbus: Camion, microbus, combi

- Metro: metro, suburban train

- Bus: Metrobus, Ecobus

- Shared taxi

Finally, significant for the evaluation of new mobility platforms is the degree of complementarity with other modes. That is to say, which modes are combined, to complete a trip. Figure 3 shows the modes used for access to and egress from Jetty vehicles. Trips are separated by morning and afternoon, given that in the morning trips are from home to work and in the afternoon travelers return home. Only the top 10 mode combinations are shown, which encompasses 92.5\% (access) and 95.4\% (egress) of all mode combinations. In general, walking is the most common way to access to and egress from Jetty vehicles. In the morning, walking is used for access in $27 \%$ of trips and for egress in $72 \%$ of trips. The fact that the predominance of walking as egress mode is not so marked for access might be partially explained by the spatial structure of Jetty trips, shown in Figure 1: trips origins are spread out in large areas of the city, whereas destinations are concentrated in a few trip attractors. People are willing to take motorized vehicles in the morning to access a pick-up point to board a Jetty vehicle, which is dropping off the traveler at walking distance from their jobs in a majority of cases. In the evening, the large difference between walking as access mode vs egress mode vanishes, in which other factors might be at play, such as the performance of other activities after work (before taking the Jetty vehicle) and the fact that commuters might have lower values of travel time savings and of travel time reliability in the afternoon, when they go back home, than in the morning (Carrion and Levinson, 2012). 
Table 2: Mode replacement by Jetty: rates of modal substitution per mode (left half) and combinations of modes with the largest number of preferences (right half)

\begin{tabular}{|c|c|c|c|c|c|}
\hline \multicolumn{3}{|c|}{ Disaggregated modes } & \multicolumn{3}{|c|}{ Combined modes - top 15 combinations } \\
\hline Modal substitution & $\mathbf{N}$ & Percentage & Modal substitution & $\mathbf{N}$ & Percentage \\
\hline Metro & 1273 & $51.2 \%$ & Microbus+Metro & 482 & $19.4 \%$ \\
\hline Camion (Bus) & 800 & $32.2 \%$ & Car & 283 & $11.4 \%$ \\
\hline Car, as driver & 608 & $24.5 \%$ & Microbus & 130 & $5.2 \%$ \\
\hline Ridesourcing/E-hailing & 549 & $22.1 \%$ & Taxi & 130 & $5.2 \%$ \\
\hline Microbus & 463 & $18.6 \%$ & Taxi+Metro+Microbus & 128 & $5.2 \%$ \\
\hline Shared taxi & 275 & $11.1 \%$ & Car+Taxi & 118 & $4.8 \%$ \\
\hline Car, as passenger & 266 & $10.7 \%$ & Metro+Bus+Microbs & 102 & $4.1 \%$ \\
\hline Ecobus & 262 & $10.6 \%$ & Metro & 88 & $3.5 \%$ \\
\hline Metrobus & 259 & $10.4 \%$ & $\begin{array}{l}\text { Metro+Microbus+ } \\
\text { Shared taxi }\end{array}$ & 83 & $3.3 \%$ \\
\hline Combi & 215 & $8.7 \%$ & Metro+Microbus+ Car & 81 & $3.3 \%$ \\
\hline Taxi & 206 & $8.3 \%$ & Metro+Bus & 66 & $2.7 \%$ \\
\hline Suburban train & 112 & $4.5 \%$ & Bus+Microbus & 65 & $2.6 \%$ \\
\hline Motorcycle & 27 & $1.1 \%$ & Metro+taxi & 57 & $2.3 \%$ \\
\hline $\begin{array}{l}\text { would not have } \\
\text { travelled }\end{array}$ & 42 & $1.8 \%$ & Bus & 50 & $2.0 \%$ \\
\hline Total modes & 5357 & $215.8 \%$ & Car+microbus & 46 & $1.9 \%$ \\
\hline Total trips & 2484 & $100.0 \%$ & $\begin{array}{l}\text { Trips top } 15 \\
\text { combinations }\end{array}$ & 1909 & $77 \%$ \\
\hline Average modes per trip & 2.2 & & & & \\
\hline
\end{tabular}



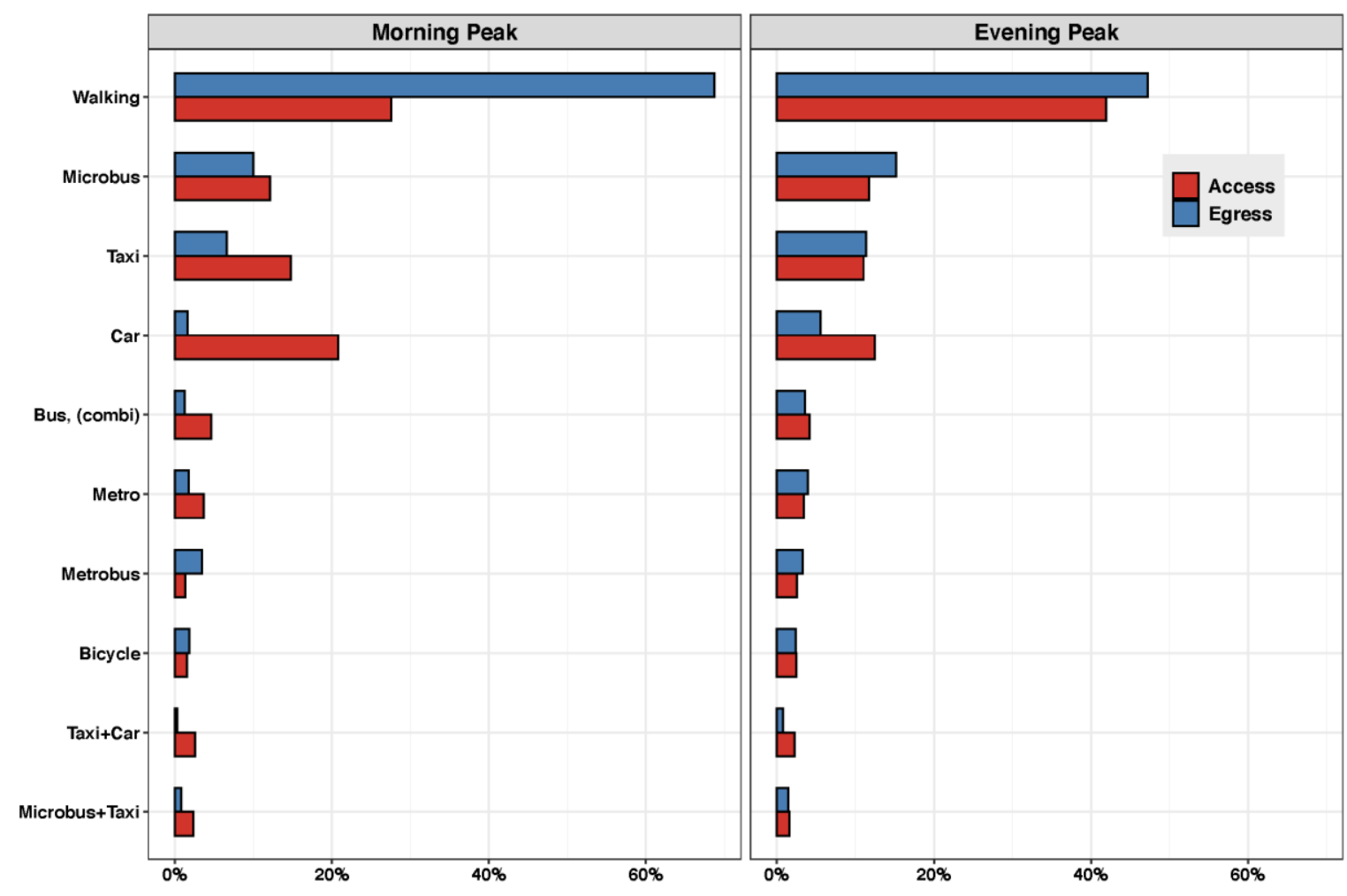

Figure 3: Top 10 modes for access to and egress from Jetty trip leg

\section{Traffic impacts of Jetty}

Following the procedure described in Section 2.4, we estimate the effect of Jetty in the number of vehicle kilometers by motorized traffic in ZMVM. The analysis is done for a subsample of 1118 users representing $89 \%$ of the valid zip codes with correct origin and destinations (the rest of survey respondents did not provide valid zip codes for origin and/or destination zones). The main reason that the total correct zip codes are not included in the analysis is that some of the survey respondents were not in the trip database provided by Jetty, as the Jetty database covers only the latest six months of usage. First, we estimate vehicle kilometers and passenger kilometers of Jetty users, as shown in Table 3. Ten Jetty vehicle types are used by the survey respondents, with vehicle capacities as in Table 3. Estimation of the following variables is first pursued:

- Number of passengers per vehicle type in the sample. Jetty provided us with data that include the vehicle type of the latest trip performed by each survey respondent, before responding to the survey. In total, $4 \%$ of trips are made in cars, $37 \%$ of trips are made in vans and $59 \%$ of trips are made in buses.

- Average demand per vehicle run, defined as the average number of passengers that use a vehicle during one run, for all vehicle types. This was provided by Jetty and it is average demand for June 2019.

- Equivalency factors of vehicles, to be translated into VKT at a common passenger car equivalency (PCE) factors. Equivalency factors are proportional to the minimum headway between two consecutive vehicles, therefore larger vehicles have larger equivalency factors 
relative to passenger cars. PCE factors represent the number of passenger cars that would have an equivalent effect on the traffic flow (Zhou et al., 2019). PCE equivalency factors between 1.5 and 2.5 are common for trucks and buses according to size (TRB, 2010; Pajecki et al., 2019; Zhou et al., 2019). PCE values between 1.5 and 2.5 for minibuses, standard buses and large (BRT) buses are adopted in Table 4.

- Passenger-kilometers traveled: This information is extracted from the Jetty database on the latest trips performed by the 1118 users in the subsample.

Concerning the trips performed in the latest six months, the number of trips and the corresponding route lengths were reported by Jetty. From this database, it is estimated that the average trip length (i.e., the average distance traveled by users) is $24.9 \mathrm{~km}$ and the average route length (i.e., the average length of the routes defined by Jetty) is $26.3 \mathrm{~km}$. An equivalent of vehicle kilometers per vehicle type is calculated in our sample, by estimating the number of equivalent rides per vehicle type in the sample [columns $(2) /(3)$ in Table 3], times the average route length per vehicle type, which is estimated as the average trip length [columns (5)/(2)], times the average ratio of route length to trip length $(26.3 \mathrm{~km} / 24.5 \mathrm{~km}=1.07)$, times vehicle equivalency (PCE) factors [column (4)].

$V K T=\frac{\text { Pax No(2) }}{\text { Avg Demand (3) }} \times$ Average trip length $\left(\frac{\text { Pax }-K m(5)}{\text { Pax No(2) }}\right) \times\left(\frac{\text { Avg route length }}{\text { Avg trip length }}\right) \times$ PCE factor (4)

The value of VKT estimated using this procedure is shown in column (6). Columns (7) and (8) show Passenger-kilometers traveled (PKT) and VKT per vehicle type, as a percentage of total PKT and VKT, respectively. Finally, column (9) is simply the ratio of (8) to (7). Columns (7) to (9) show the disproportionate effect of passengers traveling in small vehicles ("Car" type) on VKT, as compared to passengers traveling in larger vans and buses. For example, people traveling in Jetty shared cars represent $2.3 \%$ of passenger kilometers, but $8.2 \%$ of vehicle kilometers on the sample. At the other extreme of the spectrum, passengers traveling in buses with 45 seats, amount to $33.6 \%$ of PKT, but only to $25.0 \%$ of VKT this shows the adverse impact of the small Jetty vehicles on the VKT. Small vehicles are used in new routes, where there is no enough demand to operate with buses or minibuses.

Table 3: Jetty vehicle-kilometers and passenger-kilometers per vehicle type

\begin{tabular}{|c|c|c|c|c|c|c|c|c|c|}
\hline $\begin{array}{l}\text { Veh. } \\
\text { type }\end{array}$ & $\begin{array}{c}\text { Capacity } \\
\text { [seats/veh] } \\
\text { (1) }\end{array}$ & $\begin{array}{c}\text { Number } \\
\text { of users } \\
\text { in sample } \\
(2)\end{array}$ & $\begin{array}{c}\text { Average } \\
\text { demand per } \\
\text { run } \\
\text { [pax/veh] } \\
\text { (3) }\end{array}$ & $\begin{array}{c}\text { Equiv. } \\
\text { factor } \\
\text { [PCE/veh] } \\
\text { (4) }\end{array}$ & $\begin{array}{c}\text { Pax-km } \\
\text { traveled } \\
\text { (PKT) } \\
\text { (5) }\end{array}$ & $\begin{array}{l}\text { Veh-km } \\
\text { traveled } \\
\text { (VKT) } \\
(6)\end{array}$ & $\begin{array}{c}\text { РКT\% } \\
(7) \\
\end{array}$ & $\begin{array}{c}\text { VKT\% } \\
(8) \\
\end{array}$ & $\begin{array}{c}\text { VKT\%/ } \\
\text { РКT\% } \\
(9) \\
\end{array}$ \\
\hline Car & 3 & 33 & 2 & 1.0 & 641 & 344 & $2.3 \%$ & $8.2 \%$ & 3.5 \\
\hline Caddi & 6 & 11 & 3.4 & 1.0 & 272 & 84 & $1.0 \%$ & $2.0 \%$ & 2.0 \\
\hline \multirow[b]{4}{*}{ Van } & 13 & 122 & 7 & 1.3 & 2718 & 525 & $9.9 \%$ & $12.5 \%$ & 1.3 \\
\hline & 14 & 153 & 7.4 & 1.3 & 3499 & 648 & $12.8 \%$ & $15.4 \%$ & 1.2 \\
\hline & 17 & 71 & 9.6 & 1.3 & 1941 & 277 & $7.1 \%$ & $6.6 \%$ & 0.9 \\
\hline & 19 & 70 & 11.4 & 1.5 & 2172 & 301 & $7.9 \%$ & $7.2 \%$ & 0.9 \\
\hline \multirow[b]{4}{*}{ Bus } & 30 & 1 & 13.2 & 1.7 & 26 & 3.5 & $0.1 \%$ & $0.1 \%$ & 0.9 \\
\hline & 41 & 148 & 15 & 2.0 & 3431 & 479 & $12.5 \%$ & $11.4 \%$ & 0.9 \\
\hline & 42 & 145 & 15 & 2.0 & 3519 & 492 & $12.8 \%$ & $11.7 \%$ & 0.9 \\
\hline & 45 & 364 & 18.4 & 2.0 & 9194 & 1048 & $33.5 \%$ & $25.0 \%$ & 0.7 \\
\hline Total & & 1118 & 10 & & 27433 & 4200 & $100 \%$ & $100 \%$ & \\
\hline
\end{tabular}


We also estimate the VKT induced by road modes that riders use to access to and/or egress from Jetty vehicles. It should be noted that walking, which is the main access and egress mode to Jetty does not influence motorized VKT. However, for motorized modes, the following information and assumptions are required:

- Average occupancy rate per type of vehicle and service. In Mexico City there is only information about the average occupancy rate for cars, which is 1.3 pax/veh for commuting trips (INEGI, 2017). In our database, the total travel distance of car as driver is $2812 \mathrm{~km}$ and of car as passenger is 678 $\mathrm{km}$; we choose occupancy rates of car as driver and car as passenger to be $1.08 \mathrm{pax} / \mathrm{veh}$ and 2.08 $\mathrm{pax} /$ veh, respectively, because the distance-weighted average of these occupancy rates is 1.3 , as measured in Mexico City. We assume the same occupancy rate for taxi and ridesourcing, while with passengers. For PT, there is no available information, therefore, we assume base values and then make a sensitivity analysis over these assumptions. The base values of average occupancy rates are $10 \mathrm{pax} / \mathrm{veh}$ for combi and microbus and $40 \mathrm{pax} / \mathrm{veh}$ for Metrobus (BRT), which is within the range of bus occupancy rates in Santiago (Tirachini and Gomez-Lobo, 2020). The alternative scenarios tested, over these base values, are to double and to reduce by half the assumed average occupancies of PT modes (given that, as explained, there is no information of those occupancy rates in Mexico City). These scenarios are called A2 in Tables 4 and 5 and are referred to as low occupancy PT (base public transportation occupancies reduced by half) and high occupancy PT (base public transportation occupancy doubled). These average values need to take into account the whole lengths of routes, i.e., including areas of low and high occupancy.

- For modes whose distance is calculated using a shortest-path algorithm (i.e. car, combi, microbus, taxi and ridesourcing/e-hailing), a distance deviation factor over the shortest-path was included. For combi and microbus, average deviation is assumed to be $15 \%$, which is the average distance deviation for shared ridesourcing (ride-splitting) as estimated in China (Li et al., 2019) and is within the range of values for bus deviation factors assumed in Santiago (Tirachini and Gomez-Lobo, 2020). For car and taxi, a 5\% deviation is included, because car and taxi drivers do not necessarily follow shortest paths. Finally, for ridesourcing and taxi e-hailing trips, no deviation from the shortest path is assumed.

- For taxis and ridesourcing/e-hailing, an estimation of empty kilometers as a percentage of passenger-kilometers is included in the estimation of VKT. Because there are no data in Mexico City about empty kilometers, we use data from a secondary source. Several authors have provided estimations of empty kilometers by taxis and ridesourcing, of special interest is Cramer and Krueger (2016), who for two cities (Seattle and Los Angeles) estimate empty kilometers for both taxis and ridesourcing (UberX). In both cities, on average, taxi and ridesourcing empty kilometers are $60 \%$ and $40 \%$ of passenger-kilometers, respectively. These two factors, $60 \%$ for taxis and $40 \%$ for UberX, are assumed as extra empty kilometers for taxis and ridesourcing/e-hailing in our estimations, Table 4 shows all the assumptions used in the calculation process.

In our estimation, we include empty kilometers from Jetty as well. These kilometers are not fully measured by the company, as in the mornings, drivers take vehicles from home or from a depot nearby the origin of routes, and then, after the morning trip, vans and buses are parked nearby to wait for the afternoon peak. As a precise estimation is not available, we do a sensitivity analysis on the value of total VKT, for different levels of empty kilometers introduced as percentages of actual route length (same with taxis and ridesourcing). Total VKT is estimated based on four assumptions of average increases in VKT due to empty 
kilometers: $0 \%, 10 \%, 20 \%$ and $30 \%$. For example, for Scenario 1, total Jetty VKT estimated using this procedure is $7089,7509,7929$ and 8349 PCU-km for $0 \%, 10 \%, 20 \%$ and $30 \%$ of added empty kilometers, including motorized traffic used as access or egress modes.

Finally, using the procedure explained in Section 2.4 and the assumptions outlined above for Jetty VKT estimation, we estimate the total VKT replaced by Jetty, using the answers of survey respondents to which modes they would have used if Jetty were not available. With regards to supply adjustment of replaced modes, three alternative assumptions are made:

1. All modes adjust supply levels as a response to reduced demand due to Jetty, including other PT modes. This is the scenario assumed in Tirachini and Gomez-Lobo (2020) for the estimation of VKT impacts of Uber in Santiago. This scenario is regarded as a long term reaction and is unclear if it will ever materialize, given that apps such as Jetty for collaborative transport have the potential to be incorporated as part of the PT system in the future, either developed by private entrepreneurs or by the state, if public transportation rides are possible to be booked with technology such as a smartphone app in the official PT system.

2. Low occupancy vehicles (private cars, taxis, e-hailing and ridesourcing) reduce kilometers. This scenario assumes that apart from private car kilometers being saved, taxi/e-hailing and ridesourcing drivers also adjust behavior and reduce kilometers driven if demand drops, in a way to keep constant passenger occupancy rates and empty kilometers. This is regarded as a mediumterm reaction.

3. Only kilometers by private car are saved. Therefore, all other modes such as taxi, ridesourcing and different PT alternatives continue running at the same level, despite demand losses to Jetty. This is regarded as a very short-term situation, in which there is no supply adjustments to demand.

Table 4: Parameters assumed for VKT calculations

\begin{tabular}{|l|c|c|c|c|c|c|c|}
\hline & \multicolumn{4}{|c|}{ Replaced modes } & \multicolumn{2}{c|}{ Jetty } \\
\cline { 2 - 7 } \multicolumn{1}{|c|}{ Mode } & $\begin{array}{c}\text { Scenarios } \\
\text { A, B }\end{array}$ & $\begin{array}{c}\text { Scenario A2 } \\
\text { Low Occ. }\end{array}$ & $\begin{array}{c}\text { Scenario } \\
\text { A2 High } \\
\text { Occ. }\end{array}$ & $\begin{array}{c}\text { PCE } \\
\text { factor }\end{array}$ & $\begin{array}{c}\text { Route } \\
\text { Diversion } \\
\text { factor }\end{array}$ & $\begin{array}{c}\text { Jetty Veh. } \\
\text { Capacity }\end{array}$ & $\begin{array}{c}\text { Eq. Size } \\
\text { factor }\end{array}$ \\
\hline Camion, Bus & 20 & 10 & 40 & 2 & 1.15 & 3 & 1 \\
\hline Car, as driver & 1.08 & 1.08 & 1.08 & 1 & 1.05 & 6 & 1 \\
\hline $\begin{array}{l}\text { Car, as } \\
\text { passenger }\end{array}$ & 2.08 & 2.08 & 2.08 & 1 & 1.05 & 13 & 1.3 \\
\hline Combi & 10 & 5 & 20 & 1.5 & 1.15 & 14 & 1.3 \\
\hline Ecobus & 30 & 15 & 60 & 2 & 1 & 17 & 1.3 \\
\hline Metrobus & 40 & 20 & 80 & 2.5 & 1 & 19 & 1.5 \\
\hline Microbus & 10 & 5 & 20 & 1.5 & 1.15 & 30 & 1.7 \\
\hline Motorcycle & 1 & 1 & 1 & 0.5 & 1.05 & 41 & 2 \\
\hline Shared Taxi & 3 & 1.5 & 4 & 1 & 1.1 & 42 & 2 \\
\hline Taxi & 1.27 & 1.27 & 1.27 & 1 & 1.05 & 45 & 2 \\
\hline $\begin{array}{l}\text { Ridesourcing } \\
\text { /E-hailing }\end{array}$ & 1.27 & 1.27 & 1.27 & 1 & 1 & & \\
\hline
\end{tabular}


Under these assumptions, we are finally able to compute the effect of Jetty on VKT, for the subsample of 1118 trips for which we have full origin-destination information. Results are shown in Table 5. In scenario A (which assumes a larger distance traveled by public transportation vehicles than by low occupancy vehicles in the replaced trip), Jetty saves VKT in the long term scenario in which all other modes adjust their supply (Scenario A.1). If only low occupancy vehicles adjust their supply, then the effect of Jetty on VKT depends on the rate of empty kilometers introduced by the platform into the road network; savings of VKT are only achieved if empty kilometers are kept very low (lower than 10\%, Scenario A2). If empty kilometers are between $10 \%$ and $20 \%$, there is an increase between $2 \%$ and $8 \%$ of VKT. In the short term, if only kilometers by private cars are replaced by Jetty, then there is an unmistakable increase in VKT (Scenario A.3). The same trend is maintained in Scenarios B (in which kilometers by shortest-paths modes are divided equally between all vehicles involved in the replaced trips, regardless if vehicles are lowoccupancy or public transportation), but, as expected, the numbers are more favorable towards VKT savings by Jetty, e.g., in Scenario B.2, VKT reductions are also possible with a rate of empty kilometers between $10 \%$ and $20 \%$.

Finally, we model an alternative scenario to A.1, in which we double or reduce by half the assumed average occupancies of public transportation modes (given that, as explained, there is no information of those occupancy rates in Mexico City). These scenarios are called A2 in Tables 4 and 5. Because this assumption only affects the case in which all modes are assumed to adjust VKT, only that case is shown for A2 in Table 5. With A2, it is shown that even though the assumed occupancy rates of public transportation do affect the estimation of VKT changes, it only changes the conclusion of a reduction in VKT if public transportation modes have a larger occupancy and the empty VKT by Jetty is $20 \%$ or larger (Scenario A2.1a).

Table 5: Estimation of change in total VKT due to Jetty

\begin{tabular}{|c|c|c|c|c|c|}
\hline \multirow[t]{2}{*}{ Scen } & \multirow{2}{*}{$\begin{array}{l}\text { Assumption on supply adjustment of } \\
\text { other modes }\end{array}$} & \multicolumn{4}{|c|}{ Jetty empty km (as percentage of commercial km) } \\
\hline & & $0 \%$ & $10 \%$ & $20 \%$ & $30 \%$ \\
\hline \multirow[t]{3}{*}{ A } & A 1 Allmodes & $-14 \%$ & $-9 \%$ & $-4 \%$ & $-0 \%$ \\
\hline & $\begin{array}{l}\text { A.2 Low occ } \\
\text { (car+taxi+ridesourcing+motorcycle) }\end{array}$ & $-3 \%$ & $2 \%$ & $8 \%$ & $14 \%$ \\
\hline & A.3 Private car only & $29 \%$ & $39 \%$ & $50 \%$ & $60 \%$ \\
\hline \multirow[t]{3}{*}{ B } & B.1 All modes & $-18 \%$ & $-14 \%$ & $-9 \%$ & $-5 \%$ \\
\hline & $\begin{array}{l}\text { B.2 Low occ (car+taxi+ridesourcing+ } \\
\text { Motorcycle) }\end{array}$ & $-9 \%$ & $-4 \%$ & $-1 \%$ & $6 \%$ \\
\hline & B.3 Private car only & $22 \%$ & $32 \%$ & $42 \%$ & $52 \%$ \\
\hline \multirow[t]{2}{*}{ A2 } & A2.1a All Modes - high occupancy PT & $-10 \%$ & $-5 \%$ & $0 \%$ & $6 \%$ \\
\hline & A2.1b All Modes - low occupancy PT & $-21 \%$ & $-17 \%$ & $-13 \%$ & $-9 \%$ \\
\hline
\end{tabular}

In Figure 4 we show the effect on VKT of each survey respondent, for Scenarios A.2; a positive value means that the user is adding VKT to the road network. 


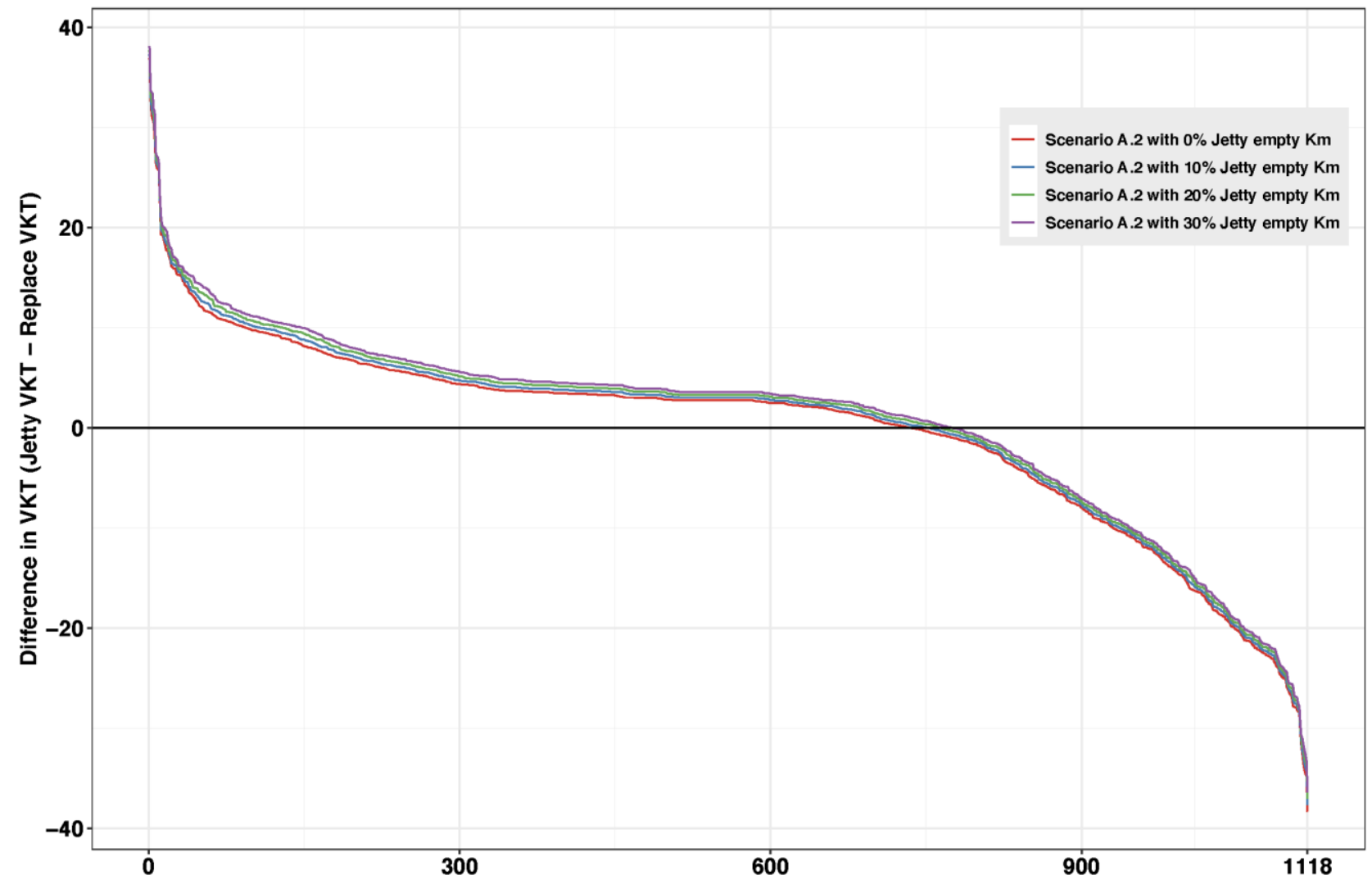

Figure 4: Difference in VKT per User

Finally, for Scenario A.2, we estimate the VKT effect per trip and per vehicle type, as shown in Table 6. Trips in cars run by Jetty are those that add the most VKT to the network (between 6.6 to $9.5 \mathrm{~km} /$ trip on average). Second, van users save VKT in all empty kilometer scenarios, with savings between -1.5 and -0.2 $\mathrm{km} /$ trip. Finally, bus users increase VKT between 0.1 and $1.1 \mathrm{~km} /$ trip. The latter result is somewhat counterintuitive, as from Table 3 we could expect that larger vehicles would have a more favorable effect in VKT than smaller vehicles, which is true when looking at vans but it is not true when looking at buses. The explanation for this finding comes for the fact that the VKT effect from different vehicle types is explained not only by the number of passengers carried by each vehicle, but also by the modes replaced. In this respect, when examining modal substitution by Jetty vehicle type, we do find relevant differences, as shown in Table 7, in which we show the substitution of combined modes, with the same mode aggregation as in Table 2. Comparing van and bus users, we see that for vans the most replaced mode is traveling by their own car (155), followed by the combination Metro+Microbus (13\%) and then by two low-occupancy alternatives: taxi (9\%) and taxi+car (7\%). On the other side, for bus users, the most replaced mode is Metro+Microbus (23\%), car replacement falls to $10 \%$, and places 3 and 4 are also combined modes that include Metro and Microbus. Therefore, we conclude that there is a larger tendency to replace low occupancy modes in van users than in bus users, and that is the reason why van users save VKT and bus users increase VKT in Scenario A2, even though buses carry more passengers per vehicle than vans. It is worth mentioning, however, that higher-quality bus services as those provided by Jetty (relative to traditional colectivos in Mexico City, as shown in Section 3.2), might be a future direction for the public transportation system in the city, in order to help stop riders from leaving public transportation in their 
daily commute. Such policy of increasing quality in public transportation should be studied in parallel with the provision of proper fare subsidies, in order to keep affordable prices for low-income users. It is also worth mentioning that different Jetty vehicle types may have different levels of empty kilometers added to the road network; however, we do not have specific data to assess such hypothesis.

Table 6: Estimation of VKT difference per trip [km/user] per Jetty vehicle type, Scenario A.2

\begin{tabular}{|l|r|r|r|r|r|}
\hline \multirow{2}{*}{$\begin{array}{l}\text { Vehicle } \\
\text { type }\end{array}$} & \multicolumn{4}{|c|}{ Jetty empty $\mathbf{~ k m ~ ( a s ~ a ~ p e r c e n t a g e ~ o f ~}$} & \multirow{2}{*}{ Users } \\
\cline { 2 - 5 } & \multicolumn{1}{c|}{$\mathbf{0} \%$} & \multicolumn{1}{c|}{$\mathbf{1 0 \%}$} & \multicolumn{1}{|c|}{$\mathbf{2 0 \%}$} & \multicolumn{1}{c|}{$\mathbf{3 0 \%}$} & \\
\hline Cars & 6.6 & 7.6 & 8.5 & 9.5 & 44 \\
\hline Vans & -1.5 & -1.1 & -0.7 & -0.2 & 416 \\
\hline Buses & 0.1 & 0.4 & 0.7 & 1.1 & 658 \\
\hline Total & -0.2 & 0.2 & 0.5 & 0.9 & 1118 \\
\hline
\end{tabular}

Table 7: Substituted (combined) mode by Jetty users, per Jetty vehicle used

\begin{tabular}{|c|c|c|c|c|c|}
\hline \multicolumn{2}{|l|}{ Car users } & \multicolumn{2}{|l|}{ Van users } & \multicolumn{2}{|l|}{ Bus users } \\
\hline Substituted mode & Pct. & Substituted mode & Pct. & Substituted mode & Pct. \\
\hline Metro+Microbus & $16 \%$ & Car & $15 \%$ & Metro+Microbus & $23 \%$ \\
\hline Taxi & $16 \%$ & Metro+Microbus & $13 \%$ & Car & $10 \%$ \\
\hline Car & $9 \%$ & Taxi & $9 \%$ & $\begin{array}{l}\text { Metro+Microbus+Tax } \\
\text { i }\end{array}$ & $6 \%$ \\
\hline Microbus & $9 \%$ & Taxi+Car & $7 \%$ & Metro+Microbus+Car & $6 \%$ \\
\hline Bus+Microbus & $7 \%$ & $\begin{array}{l}\text { Metro+Microbus+Tax } \\
\mathrm{i}\end{array}$ & $6 \%$ & Metro+Bus+Microbus & $5 \%$ \\
\hline Metro+SharedTaxi & $7 \%$ & Microbus & $5 \%$ & Microbus & $5 \%$ \\
\hline Metro+Bus+Microbus & $5 \%$ & Metro+SharedTaxi & $5 \%$ & Metro & $5 \%$ \\
\hline Bus+Microbus+Taxi & $2 \%$ & Metro+Taxi & $4 \%$ & Taxi+Car & $4 \%$ \\
\hline Bus+Taxi & $2 \%$ & $\begin{array}{l}\text { Metro+Microbus+ } \\
\text { SharedTaxi }\end{array}$ & $4 \%$ & Metro+Bus & $3 \%$ \\
\hline Metro & $2 \%$ & Metro+Bus & $3 \%$ & $\begin{array}{l}\text { Metro+Microbus+ } \\
\text { SharedTaxi }\end{array}$ & $3 \%$ \\
\hline $\begin{array}{l}\text { Metro+Bus+SharedTax } \\
\text { i }\end{array}$ & $2 \%$ & Microbus+Taxi & $3 \%$ & Bus & $3 \%$ \\
\hline Metro+Bus+Taxi & $2 \%$ & Metro+Microbus+Car & $2 \%$ & Metro+Car & $2 \%$ \\
\hline Metro+Microbus+Car & $2 \%$ & Metro+Taxi+Car & $2 \%$ & Taxi & $2 \%$ \\
\hline $\begin{array}{l}\text { Metro+Microbus+ } \\
\text { SharedTaxi }\end{array}$ & $2 \%$ & Bus+Microbus & $2 \%$ & Bus+Microbus & $2 \%$ \\
\hline Metro+Microbus+Taxi & $2 \%$ & Microbus+Car & $2 \%$ & Metro+Taxi & $2 \%$ \\
\hline $\begin{array}{l}\text { Total substitution top } \\
15 \text { modes }\end{array}$ & $86 \%$ & & $82 \%$ & & $83 \%$ \\
\hline
\end{tabular}




\section{Conclusions and policy implications}

This research focuses on the estimation of the impact that shared rides on cars, vans and buses have on vehicle-kilometers traveled (VKT). With the use of a large-scale dataset of approx. 2500 responses (for 1118 of which we were able to obtain a full dataset including origin and destination of trips), accompanied by some assumptions commonly met in the pertinent literature (for example, on occupancy rates of modes substituted by Jetty), we perform sensitivity analyses and develop different scenarios for which we evaluate possible increases or reductions of VKT. The case we examine is quite unique: Jetty is a sharedmobility platform operating in one of the largest cities in the world; it targets a market share mainly composed of middle to high-income travelers with a high percentage of private vehicles in the household (double than the national average). Therefore, given the characteristics of its users, Jetty has the potential to replace a significant number of personal car trips. Another main characteristic of Jetty is that the operational routes serve trips whose origins and destinations are underserved by other direct connections and means of public transportation, as $74 \%$ of the sample would need two or more modes in combination to complete the latest trip made in Jetty, if Jetty was not available. Given that Jetty is an app for shared trips, its rate of replacement of other shared or public transportation modes is larger than the rates reported in ridesourcing studies.

When ranking the reasons to use Jetty, we observe that the possibility of booking a seat, security against theft, trip duration and travel time reliability are the most valued attributed by Jetty users, whereas security against harassment has the largest difference in valuation between male and female riders. A large percentage of the platform users are substituting traditional modes of transport for reasons other than travel time, which points to the relevance and valuation of quality of service attributes within the context of disrupting mobility technologies. Regarding VKT, our results show that (i) there is an increase in VKT if only kilometers by private cars are assumed to be ceased because of Jetty, (ii) there is a reduction in VKT if all replaced modes (including private and public transportation) are assumed to adjust their supply in order to keep their occupancy levels per trip constant, and that (iii) the VKT result depends on the rate of empty kilometers that Jetty introduced to the network, in the case in which only low occupancy vehicles (private cars plus taxis/e-hailing and ridesourcing) are assumed to adjust their kilometer supply. Therefore, the effect of this new service on vehicle-kilometers in the city largely depends on the time-line of the analysis being performed (short-term versus long- term effects) and on the management and optimization of empty kilometers by the service provider.

This conclusion adds to the literature that points to the relevance of shared rides and increasing the occupancy rates of vehicle trips, for new mobility technologies, such as ridesourcing and automated vehicles, to reduce or at least not to increase traffic in cities (Sterling, 2018; Tirachini, 2019; Narayanan et al., 2020). The analysis of VKT per type of Jetty vehicle shows an interesting outcome, as the effect on potentially reducing VKT of Jetty vans is better than the effect of Jetty buses, which is explained because van users replace more trips by low occupancy vehicles than bus users; this modal substitution effect overcomes the fact that buses have a larger passenger occupancy rate per vehicle than vans in our estimations. Therefore, well-tailored routes on middle-size vans seem to be attracting more car users than Jetty buses. At this point, this negative result for buses should be qualified in a broader sense, by also including the effect of these new on-demand bus services on retaining travelers in large occupancy vehicles, i.e., analyzing the possible effect of these buses in stopping people from switching from lowquality colectivos straight to driving cars. Such potential long-term effects are not possible to analyze with 
our data. It is also relevant to note that higher-quality bus trips (which is the case analyzed in our study), might be the way forward of the whole public transportation system in the future.

The fact that shared rides in vans can indeed reduce VKT is a significant finding in the strand of literature on the sustainability effects of app-based mobility platforms. Unlike the latest studies on (unshared) ridesourcing that estimate an increase of motorized traffic and congestion due to ridesourcing platforms (Nie, 2017; Erhardt et al., 2019; Henao and Marshall, 2019; Wenzel et al., 2019; Tirachini and GomezLobo, 2020), our analysis shows that sharing rides in middle-size vehicles results in an opposite effect. A reduction of VKT due to the partial replacement of trips that otherwise would be made in low occupancy vehicles, together with an improvement in the quality of service experience by users, is good news for the sustainability of present and future mobility patterns in cities. It is to be seen if such result holds with services targeting a larger demand (both geographically and in terms of socioeconomic characteristics) and in other urban environments.

The policy implications of our findings are wide. Our results point to the relevance of innovative ridesharing schemes in bigger vehicles, such as vans, as competitors to low occupancy car services for the future of sustainable mobility in cities. This finding can support related policies and encourage policymakers to steer their strategies and incentives towards such services. On the other hand, Jetty buses may increase VKT based on our results, but they are still buses offering a new type of public transportation services. As discussed, an integration into the public transportation system could provide synergies with broader benefits for the overall system, that is to say, authorities could explore the adoption of booking technologies and higher quality services as part of the public transportation system of Mexico City. An alternative approach could also be taken by allowing (upon certain conditions) the start-up business ecosystem to target sustainable mobility options. If this happens in cooperation with public transportation authorities, it might substitute trips that would otherwise happen using cars, something that might also have long term effects such as reduction of car-trips and car-ownership.

Naturally, integration and cooperation to and with the official public transportation system pose the challenge of social equity, as the added cost of enhanced services would have to be covered by additional subsidies to make such services affordable by the general population. Furthermore, less tech-savvy segments of the population or citizens with limited access to smartphones might be excluded from such services. There is also the risk of public transportation with different qualities used exclusively by specific income groups, endangering social cohesion and deepening income inequality. These challenges should be addressed in a balanced manner, aiming at reducing car dependency and excessive car use in congested cities, while safeguarding public transportation as a mean to enhance social cohesion. The equity effects of new shared and public transportation services are particularly relevant in the context of Mexico City and other large conurbations in developing countries, characterized by several forms of social inequality.

Other take-away lessons to be learned are that Jetty users do not only choose the service because of travel time; there are other significant factors that can encourage travelers to switch to shared-mobility modes. These findings could be used to adapt other (including public transportation as discussed before) services, so that they are more appealing to specific segments of the population. Of course, these conclusions can also be useful for developing shared-mobility services similar to Jetty in other cities in the world, but also for a potential refinement of Jetty's services in Mexico City. 
Finally, our results also highlight the relevance of the number of empty kilometers that a shared-mobility provider adds to the road network of a city. An efficient management of empty kilometers with tactical decisions (e.g., long-term actions such as the renting of parking slots or terminals in the proximity of route destinations) as well as with operational decisions (e.g., day-to-day vehicle scheduling and route optimization) is of utter importance to improve the chances of motorized shared-mobility modes to reduce traffic in cities.

The available dataset is very rich and can support a multitude of additional analyses. Future research directions include (i) optimizing the network structure of the Jetty operation, as well as the allocation of vehicles to specific routes, (ii) developing policy interventions and schemes that can support the operation of such services, in a way conducive to the reduction of overall VKT, energy consumption and emissions, (iii) examine the impact of such services on transport equity, (iv) explore innovative and dynamic pricing schemes and mechanisms, including fare and operational integration into the city public transportation system, or ( $v$ ) explore the impact of vehicle automation on the system operations, using the latest results on the effects of automation for shared vehicles and public transportation services (Fielbaum, 2019; Narayanan et al., 2020; Tirachini and Antoniou, 2020) and (vi) analyze if different vehicle types (cars, vans and buses) have different rates of empty kilometers. The study of the optimal economic regulation of ridesourcing (Zha et al., 2016) should be extended to the case of shared or pooled rides. Another direction of research is the collection of similar data from other systems in the world, to analyze the results comparatively and try to understand which might be general results and which might be context-specific.

\section{Declarations of interest}

None.

\section{Acknowledgments}

This paper is part of a research collaboration set up in 2019 between the Chair of Transportation Systems Engineering of the Technical University of Munich (TUM) and Jetty. We thank Jetty for allowing us to independently conduct a survey to its users, without compromising research integrity and independence, as the survey and its data collection process were fully managed by the authors. Part of this paper was written while the first author was Fellow of the Humboldt Foundation at TUM. This research has been partly supported by the German Research Foundation - Deutsche Forschungsgemeinschaft (DFG, Project number 392047120)], the TUM International Graduate School of Science and Engineering - IGSSE (MO3 Project) and CONICYT Chile (PIA/BASAL AFB180003). We are indebted to three anonymous reviewers for detailed comments that helped us to improve the final version of our paper.

\section{References}

Agarwal, S., D. Mani and R. Telang (2019). The Impact of Ride-hailing Services on Congestion: Evidence from Indian Cities. Working paper, available at SSRN: https://ssrn.com/abstract=3410623.

Alonso Ferreira, M., F. T. Salva Rocha, A. Giuli and F. de Mello Franco (2018). Politics, polity and policy of ridesourcing regulation in São Paulo. Urban Transport in the Sharing Economy Era: Collaborative Cities. CIPPEC, Argentina. https://www.cippec.org/wp-content/uploads/2018/09/UrbanTransport-completoweb CIPPEC.pdf.

Bansal, P., R. Hurtubia, A. Tirachini and R. A. Daziano (2019). Flexible estimates of heterogeneity in crowding valuation in the New York City subway. Journal of Choice Modelling 31: 124-140. 
Beer, R., C. Brakewood, S. Rahman and J. Viscardi (2017). Qualitative Analysis of Ride-Hailing Regulations in Major American Cities. Transportation Research Record 2650: 84-91.

Brown, A. (2018). Ridehail Revolution: Ridehail Travel and Equity in Los Angeles. PhD thesis, University of California Los Angeles.

Carrion, C. and D. Levinson (2012). Value of travel time reliability: A review of current evidence. Transportation Research Part A 46(4): 720-741.

Circella, G., F. Alemi, K. Tiedeman, S. Handy and P. Mokhtarian (2018). The Adoption of Shared Mobility in California and Its Relationship with Other Components of Travel Behavior Report, National Center for Sustainable Transportation, United States.

Clewlow, R. R. and G. S. Mishra (2017). Disruptive Transportation: The Adoption, Utilization, and Impacts of Ride-Hailing in the United States. Research Report - UCD-ITS-RR-17-07, UC Davis Institute of Transportation.

Cramer, J. and A. B. Krueger (2016). Disruptive change in the taxi business: the case of Uber. NBER Working Paper 22083.

dell'Olio, L., A. Ibeas and P. Cecin (2011). The quality of service desired by public transport users. Transport Policy 18(1): 217-227.

Ditmore, C. J. and D. M. Deming (2018). Vanpooling and its effect on commuter stress. Research in Transportation Business \& Management 27: 98-106.

Dong, Y., S. Wang, L. Li and Z. Zhang (2018). An empirical study on travel patterns of internet based ridesharing. Transportation Research Part C: Emerging Technologies 86: 1-22.

Erhardt, G. D., S. Roy, D. Cooper, B. Sana, M. Chen and J. Castiglione (2019). Do transportation network companies decrease or increase congestion? Science Advances 5(5): eaau2670.

Fielbaum, A. (2019). Strategic public transport design using autonomous vehicles and other new technologies. International Journal of Intelligent Transportation Systems Research. DOI https://doi.org/10.1007/s13177-019-00190-5.

Flores Dewey, O. (2018). App-Based Collective Transport Service in Mexico City: A Start-Up Case Study. International Transport Forum Discussion Papers, OECD Publishing, Paris.

Graehler, M., R. A. Mucci and G. D. Erhardt (2019). Understanding the recent transit ridership decline in major US cities: service cuts or emerging modes? 98th Annual Meeting of the Transportation Research Board (TRB), Washington D.C.

Hall, J. D., C. Palsson and J. Price (2018). Is Uber a substitute or complement for public transit? Journal of Urban Economics 108: 36-50.

Henao, A. (2017). Impacts of ridesourcing -LYFT and UBER-on transportation including VMT, Mode replacement, parking and Travel Behavior. Ph.D. Thesis, University of Colorado.

Henao, A. and W. E. Marshall (2019). The impact of ride-hailing on vehicle miles traveled. Transportation 46: 2173-2194.

INEGI (2015). Banco de Indicadores, Ciudad de Mexico (Databank, Mexico City). Instituto Nacional de Estadistica $\quad y \quad$ Geografia (INEGI), available at https://www.inegi.org.mx/app/indicadores/?t=0120\&ag=09\#tabMCcollapse-Indicadores, accessed 28/april/2020.

INEGI (2017). Encuesta Origen-Destino en Hogares de la Zona Metropolitana del Valle de Mexico (EOD 2017) (in spanish). Report, Instituto Nacional de Estadistica y Geografia (INEGI).

Kircher, D. and L. Wapensky (1978). Vanpooling: An Overview. Publication EPA-908/1-78- 001 (Denver, CO: US Environmental Protection Agency, Region VIII).

Lavieri, P. S. and C. R. Bhat (2019). Investigating objective and subjective factors influencing the adoption, frequency, and characteristics of ride-hailing trips. Transportation Research Part C: Emerging Technologies 105: 100-125. 
Li, W., Z. Pu, Y. Li and X. Ban (2019). Characterization of ridesplitting based on observed data: A case study of Chengdu, China. Transportation Research Part C: Emerging Technologies 100: 330-353.

Magaloni, B. (2019). La Victimización en el Transporte en la Ciudad de México y la Zona Metropolitana. Report, Stanford Poverty Violence Governance Lab.

Márquez, L., J. V. Alfonso A and J. C. Poveda (2019). In-vehicle crowding: Integrating tangible attributes, attitudes, and perceptions in a choice context between BRT and metro. Transportation Research Part A: Policy and Practice 130: 452-465.

Narayanan, S., E. Chaniotakis and C. Antoniou (2020). Shared autonomous vehicle services: A comprehensive review. Transportation Research Part C: Emerging Technologies 111: 255-293.

$\mathrm{Nie}, \mathrm{Y}$. (2017). How can the taxi industry survive the tide of ridesourcing? Evidence from Shenzhen, China. Transportation Research Part C: Emerging Technologies 79: 242-256.

ONU Mujeres (2018). Encuesta sobre la violencia sexual en el transporte y otros espacios públicos en la Ciudad de Mexico. Report (in Spanish), UN Women.

Pajecki, R., F. Ahmed, X. Qu, X. Zheng, Y. Yang and S. Easa (2019). Estimating Passenger Car Equivalent of Heavy Vehicles at Roundabout Entry Using Micro-Traffic Simulation. Frontiers in Built Environment 5(77). Rayle, L., D. Dai, N. Chan, R. Cervero and S. Shaheen (2016). Just a better taxi? A survey-based comparison of taxis, transit, and ridesourcing services in San Francisco. Transport Policy 45: 168-178.

Shaheen, S. (2018). Shared Mobility: The Potential of Ridehailing and Pooling. Three Revolutions. Island Press, Washington, DC: 55-76.

Shaheen, S. and A. Cohen (2019). Shared ride services in North America: definitions, impacts, and the future of pooling. Transport Reviews 39(4): 427-442.

Shaheen, S., A. Cohen and I. Zohdy (2016). Shared Mobility: Current Practices and Guiding Principles. Report FHWA-HOP-16-022, Federal Highway Administration (FHWA).

Sterling, D. (2018). Three revolutions: steering automated, shared and electric vehicles to a better future. Island Press.

Tang, B.-J., X.-Y. Li, B. Yu and Y.-M. Wei (2019). How app-based ride-hailing services influence travel behavior: An empirical study from China. International Journal of Sustainable Transportation: 1-15.

Tirachini, A. (2019). Ride-hailing, travel behaviour and sustainable mobility: an international review. Transportation, https://doi.org/10.1007/s11116-019-10070-2.

Tirachini, A. and C. Antoniou (2020). The economics of automated public transport: Effects on operator cost, travel time, fare and subsidy. Economics of Transportation 21: 100151.

Tirachini, A. and M. del Río (2019). Ride-hailing in Santiago de Chile: users' characterisation and effects on travel behaviour. Transport Policy 82: 46-57.

Tirachini, A. and A. Gomez-Lobo (2020). Does ride-hailing increase or decrease vehicle kilometers traveled (VKT)? A simulation approach for Santiago de Chile. International Journal of Sustainable Transportation 14:3(3): 187-204.

TRB (2010). Highway Capacity Manual. Transportation Research Board, National Research Council, Washington D.C.

Tyrinopoulos, Y. and C. Antoniou (2008). Public transit user satisfaction: Variability and policy implications. Transport Policy 15(4): 260-272.

Wardman, M. and G. A. Whelan (2011). Twenty years of rail crowding valuation studies: evidence and lessons from British experience. Transport Reviews 31(3): 379-398.

Wenzel, T., C. Rames, E. Kontou and A. Henao (2019). Travel and energy implications of ridesourcing service in Austin, Texas. Transportation Research Part D: Transport and Environment 70: 18-34.

Zha, L., Y. Yin and H. Yang (2016). Economic analysis of ride-sourcing markets. Transportation Research Part C: Emerging Technologies 71: 249-266. 
Zhou, J., L. Rilett and E. Jones (2019). Estimating Passenger Car Equivalent using the HCM-6 PCE Methodology on Four-Lane Level Freeway Segments in Western U.S. Transportation Research Record 2673(11): 529-545. 